\title{
Roman Artistic Motifs Found on the Sculpture of Eastern Frontispiece of Abhayagiriya
}

\author{
A. Biyanwila \\ M.Phil. (Reading), Postgraduate Institute of Humanities and Social Sciences, University of Peradeniya, Peradeniya, \\ Sri Lanka \\ ayeshibiyanwila@gmail.com
}

\begin{abstract}
Ancient art is neither compact nor concise. It inspires and is inspired incessantly. Ancient Sri Lankan Art does not escape this truth. The presence of Indian influences such as Andhra, Gandhara, Mathura, Amaravati in Sri Lankan art has been discussed extensively. This paper discusses the Roman artistic influences on sculpture found at Eastern Vahalkada/frontispiece/Aika or Frontispiece of Abhayagiriya, Anuradhapura. The Roman motifs of candelabrum, cupids and griffins found at Abhayagiriya which is also composed of Acanthus foliage reminds us of ancient Roman art. This paper will analyze the said motifs extensively and it will compare each of the above motifs with the original forms and iconography to show the intended inspiration from the Roman artistic tradition. The analysis of the artistic motifs would then prove a possibility of cultural exchange between Ancient Sri Lanka and Rome which have rarely been discussed. This presence could not be missed, when it is supported by the historical proof of the presence of trade and political links between Sri Lanka and Rome. Hence, this paper will be studying a single case that will study Roman influences in Ancient Sri Lankan art and it will suffice to show that no form of art is exclusive but open and inspirational.
\end{abstract}

Keywords: Abhayagiriya, Frontispiece, Artistic Motifs, Roman Art, Sri Lanka 


\section{Introduction}

The Abhayagiriya Stupa in Anuradhapura was built by King Valagamba who is also known as King Vattagamani Abhaya (109 and 89-77 B.C.). The stupa and the monastery surrounding was donated to a monk named Kuppikala Mahatissa, which donated the first personal donation done to a Buddhist monk. Chapter 33 of Mahavamsa describes, "When two hundred and seventeen years ten months and ten days had passed since the founding of the Mahavihara the king, filled with pious zeal, built the Abhayagiri-vihara. He sent for the (two) others, and to the thera Mahatissa, who had first assisted him of the two, he gave the vihara, to do him honour. Since king Abhaya built it on the place of the arama. of (the nigantha) Giri, the vihara received the name Abhayagiri (Mahavamsa, Chapter 33).

The author of Mahavamsa, further states that "a thera known by the name Mahatissa, who had frequented the families of laymen, was expelled by the brotherhood from our monastery ${ }^{1}$ for this fault, the frequenting of lay-families. His disciple, the thera who was known as Bakalamassutissa, went in anger to the Abhayagiri (vihara) and abode there, forming a (separate) faction. And thence forward these bhikkhus came no more to the Mahavihara: thus, did the bhikkhus of the Abhayagiri (vihara) secede from the Thera (ibid). Hence it could be assumed that monk Mahatissa was accused of accepting this personal gift and was banished from Mahavihara.

Though the stupa is said to be built during the reign of Valagamba, a slab inscription found at South Vahalkada/frontispiece of the Abhayagiri stupa states that the four Vahalkada/frontispieces of the stupa have been built by King Malu Tissa or Kaniththa Tissa (164-198 C.E.) (Wickremasinghe,1912).

The research aims to answer what Roman artistic elements can be found on the said section of the frontispiece of Abhayagiriya. In answering this, the author aims to

\footnotetext{
${ }^{1}$ Mahavihara
} 
discuss three main artistic elements found on the pillar of the frontispiece. These being, the candelabrum, griffins and cupids. In return, it will show how foreign artistic traditions influenced the prevalent local traditions of art.

This paper will discuss the presence of Roman artistic influence on a sculpture found at a stone pillar of the Eastern Vahalkada/frontispiece/aika of Abhayagiri Stupa (Fig. 1). According to Bopearachchi, 'conserved in situ for more than one hundred years, this relief does not seem to have been understood by those who published it (see $\mathrm{S}$. Paranavitana,1959, p.127 and U. von Schroeder, 1990, p.82 and recently, T.G. Kulatunga, 2014, p.143-5)'. He also states that J.G. Smither (1993, pl XLIX) and A. Seneviratna (1994, p.152) illustrate the pillar but have failed to 'discuss its iconography' (Bopearachchi,2020, pp.77-80). The related archaeology has been recorded throughout history as mentioned above. But, it could be assumed that these particular sculptures related to the eastern frontispiece of Abhayagiriya have not been studied extensively based on their Roman influences. Hence, this paper tries to identify the presence of Roman inspiration deducing that certain Roman artistic motifs have been used in beautifying a single pillar at the eastern frontispiece of Abhayagiriya. This will provide much space for a discussion in studying Roman artistic influences in the ancient art of Sri Lanka. 


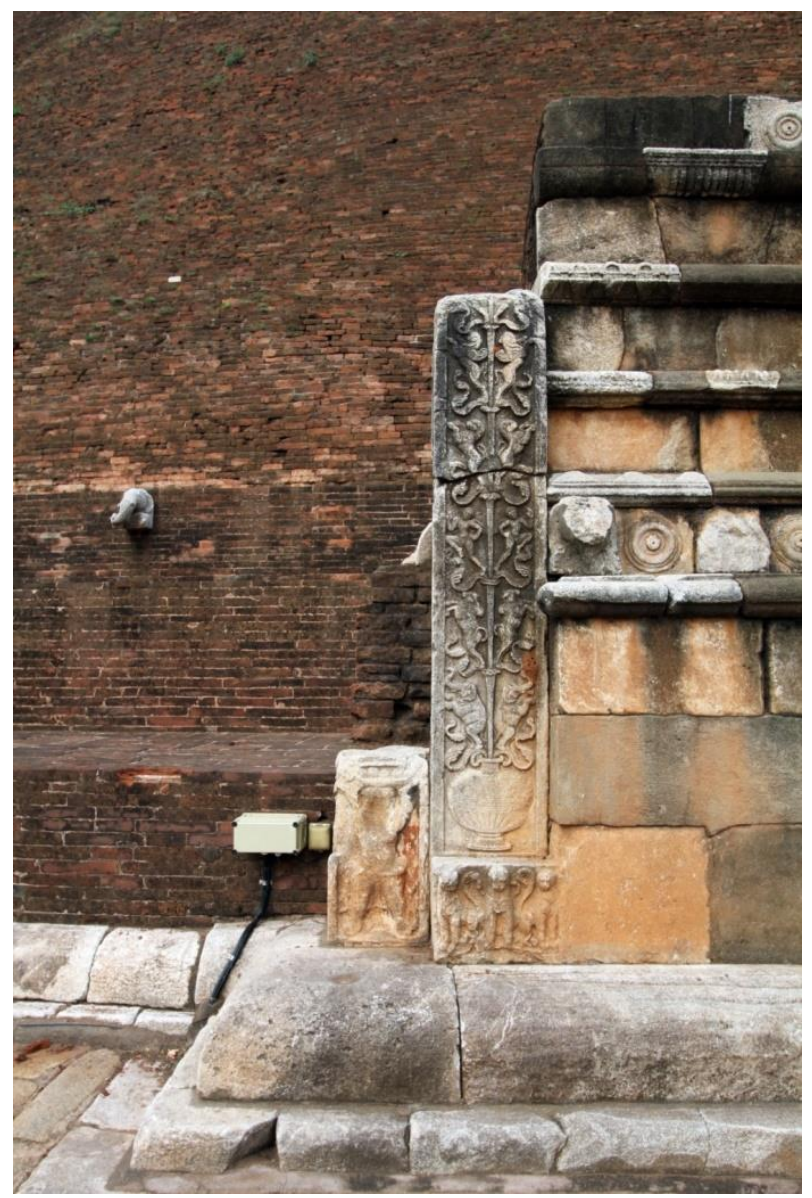

Figure 1: The Eastern Vahalkada/frontispiece/Aika of Abhayagiri Stupa

\section{Materials And Methodology}

This research uses qualitative research methods to arrive at conclusions and results. This paper will do a formal analysis of the Roman artistic features found at a stone pillar at the eastern Vahalkada/frontispiece of Abhayagiri Stupa, Anuradhapura which is believed to be built around 164-198 C.E.(Fig.2). To identify the traits of Roman origins of the said motifs, the author uses several examples from the ancient Roman world which displays the utility of the motifs. The stone pillar is of Dolamite and its height is $265 \mathrm{~cm}$, Width $47 \mathrm{~cm}$. (Bopearachchi, 2020). And a historical analysis of the Roman artistic motif of candelabrums, cupids and griffins will be done 
using several artistic depictions from Ancient Rome. Hence, the researcher tries to show the presence of roman artistic inspirations in a stone pillar that dates back to the Anuradhapura era of ancient Sri Lanka.

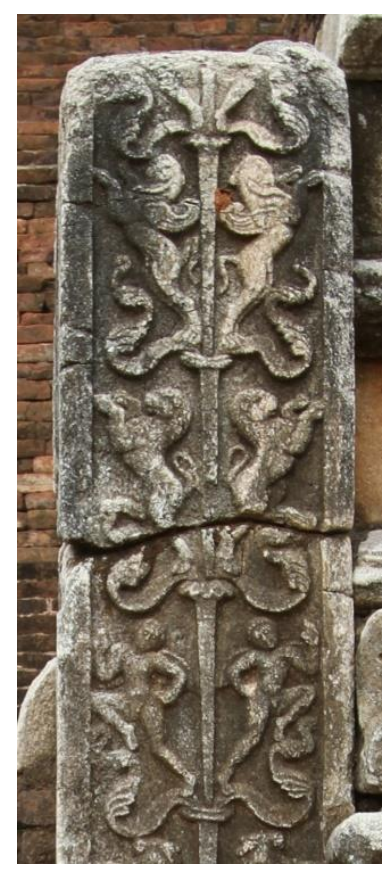

Figure 2: Griffins and Cupids, the Eastern Vahalkada/frontispiece of Abhayagiri Stupa

\section{Results and Discussion}

The formal analysis of the relief on the pillar from the Eastern Vahalkada/frontispiece of Abhayagiri Stupa can be commenced by studying the prominent basic features. Foliage emanates from a pot which is usually termed a Purnagata or Punkalasa and besides this foliage are depicted several pairs of animals and a pair of human figures. First, in the lowest corner, is a pair of elephants standing with their hind legs and then are the humped bulls raising their front legs and standing in hind legs as the elephants. Then appears a pair of human figures, identified here as the cupids. They are winged and with curly hair. Any form of clothing is not visible as in the Roman depictions of cupids. Following the cupids, appears a pair of lions and then finally the mythical creatures, who are identified as griffins. These mythical creatures are winged and are 
composed of a body of a lion and the head of a bird similar to an eagle. With the pair of griffons, the candelabrum ends. The paper will now discuss the Roman artistic motifs of the stone pillar at the Eastern Vahalkada/frontispiece of Abhayagiri Stupa, Anuradhapura in detail.

First, the motif called candelabrum will be discussed. Candelabrum is the plural of candelabra (Latin), describing the equipment which has been used to hold candles ${ }^{2}$. It is composed of a shaft to hold candles. The candelabrum would have been used in ancient Roman households. The household usage would have necessitated its ubiquitous artistic use in ancient Roman art and architecture. The motif of candelabrum in the paintings of Pompeii (A. Babet,1999, pp.76 and 81) are more artistically rendered than that of Abhayagiriya. The refinement of the Roman candelabrum is absent in the motif found at Abhayagiriya though some inspiration owing to Roman tradition is evident. The candelabrum in the paintings of Pompeii is more intricate, sometimes with female representations (Fig. 3).

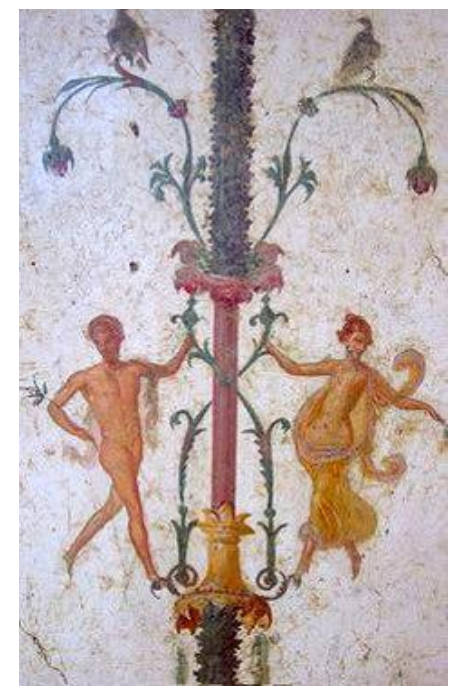

Figure 3: Candelabrum, Painting from Pompeii

National Archaeological Museum, Naples

\footnotetext{
2 Encyclopedia Britannica, Available at: https://www.britannica.com/technology/candelabrum
} 
The second Roman motif, which will be discussed here is the motif of Cupids or Eros who later became Cherubs in Victorian art. A pair of cupids can be seen as the third image from the lower end, emanating from the candelabrum with wings, of curly hair and are halfway in flight (Figure 4.1). The Cupid or Eros is popularly believed as the son of Aphrodite or Venus. The Latin term, Cupīdō [kv'pi:do:], means "passionate desire" (de Vann, 2008, p.155). He stands for passionate love and he accompanies the goddess of love with a bow and arrows often shooting arrows at men and women making them fall for their loved ones. These figures have been recurrent in the tradition of art throughout history and especially, according to Charles Brian Rose, the motif was highly popular during the reign of Augustus Caesar (63 BC-AD 14) where he states, "often included cupid personally transferring the weapons to his mother was especially popular after Actium ${ }^{3}$ " (Rose, 2005). Hence, it could be assumed that the popularity of cupid as an artistic motif has been entered the ancient artistic traditions utilized at Abhayagiriya through a medium of direct acquaintance with Rome. And these images which were used in ancient Roman art were inspirations for later western traditions of art including colonial art and architecture (Fig.4.2). Such depictions of cupids could be found in Colonial architecture in Sri Lanka as at the Coffee Planters' Fountain (Biyanwila, 2019). Before the advent of colonial art and architecture, the only instance that we could find a depiction of cupids is at the eastern frontispiece of Abhayagiriya. If these elements were highly popularized during the era of Augustus and later, this element would have probably stood to signify the Augustan legacy. Hence, the cupids have been used to denote the political supremacy or the executive aspect of the government.

\footnotetext{
${ }^{3}$ A naval battle in the last war of the Roman Republic, fought between the fleet of Octavian (Augustus) and the combined forces of Mark Antony and Queen Cleopatra of Egypt. It took place on 2 September 31 BC. (Dio Cassius 50:13)
} 


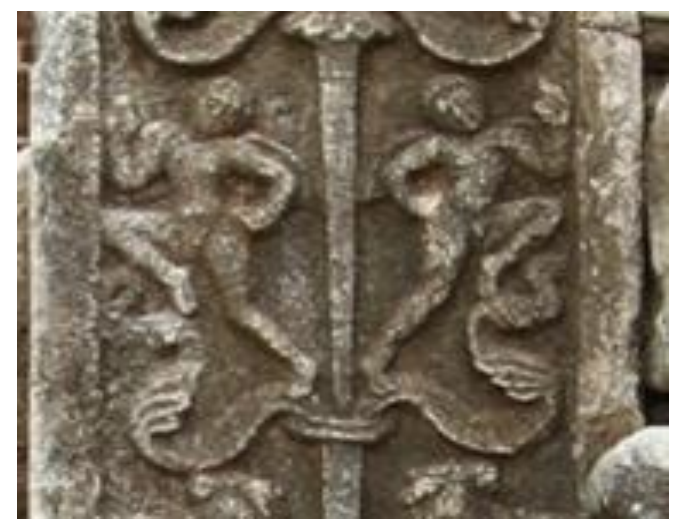

Figure 4.1: Detail of Cupids at the Eastern Vahalkada/frontispiece of Abhayagiri Stupa

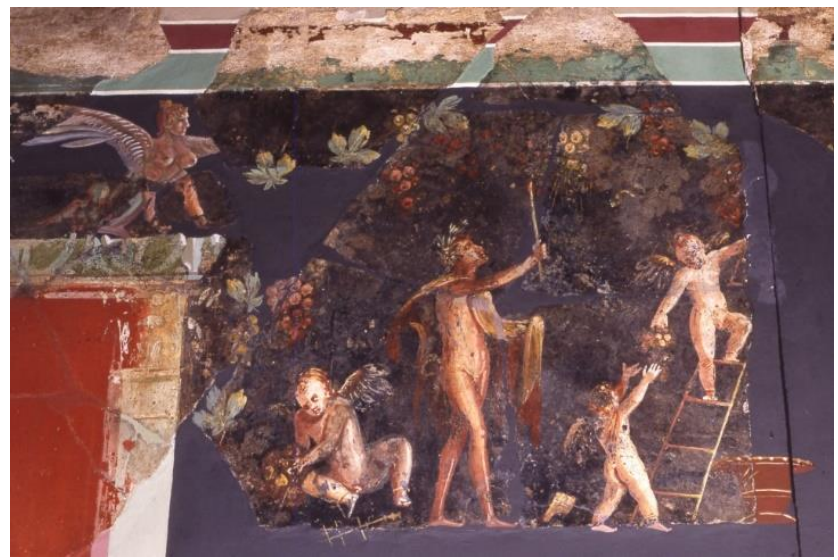

Figure 4.2: Cupids, Painting from Pompeii

National Archaeological Museum, Naples

As the third element, the motif of griffins will be discussed. The column under discussion at the Eastern Vahalkada/frontispiece of Abhayagiri Stupa depicts a pair of griffins, turned in opposite directions with their forelimbs raised. They appear at the uppermost section of the candelabrum (Figure 5.1). The griffins are winged lionlike figures with heads of birds. The word griffon, griffin or gryphon has been derived from Latin gryphu. According to Stephen Friar, "Griffin of the animals in mythology the griffin or gryphon is the most magnificent. The lion is the king of the beasts and the eagle the king of the birds, but in the griffin the majesty of the two creatures is joined together. Its head, wings and talons are those of an eagle, to which are added a pair of sharp ears, as it has very acute hearing. Its body, hindquarters and tail are 
like a lion, and thus it combined the strength and vigilance of both animals in one. The griffin was associated with the Gods in Minoan, Greek and other civilizations of the Near East. It was an animal of the sun and pulled Apollo's chariot across the sky, but it had a double role, and also pulled the chariot of Nemesis, the God of Justice. Griffins guarded the gold mines in the mountains of Scythia, and were always at war with the one-eyed Arimaspians, who tried to steal the gold to adorn their hair." (Emphasis Added) (Friar, 1987).

As emphasized earlier, the significant characteristic of griffins is that they are wellknown guards of wealth. Hence, it proves the idea that motifs were used at Vahalkada /frontispieces to denote guardianship to wealth associated with the stupa, "the prominence given to the following motifs; Kubera with his two main attendants, Sankanidhi and Padmanidhi, zoomorphic Nagas, anthropomorphic Nagaraja and Nagini and Cakravartin as the universal king making coins drop from the sky. In short, the motifs are all gods, kings, reptiles associated with wealth" (Emphasis Added) (Bopearachchi, 2020). Hence, it could be assumed that the artist who included Roman artistic motifs here, abided by the previous and contemporary local tradition of including motifs associated with wealth. The figure as stated before is a legendary creature with the body, tail and hind legs of a lion and the head of a bird. These mythical creatures have been depicted in ancient frescoes of Pompeii, now in the Naples National Archaeological Museum (Fig. 5.2). The similarity between the two instances provides proof of the relationship between the two. 


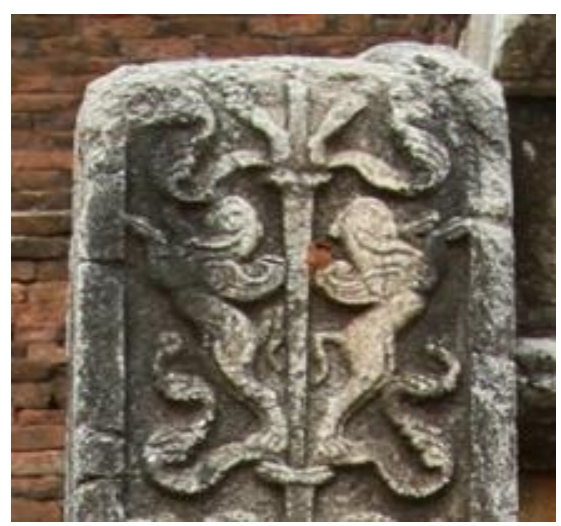

Figure 5.1: Detail of Griffins at the Eastern Vahalkada/frontispiece of Abhayagiri Stupa

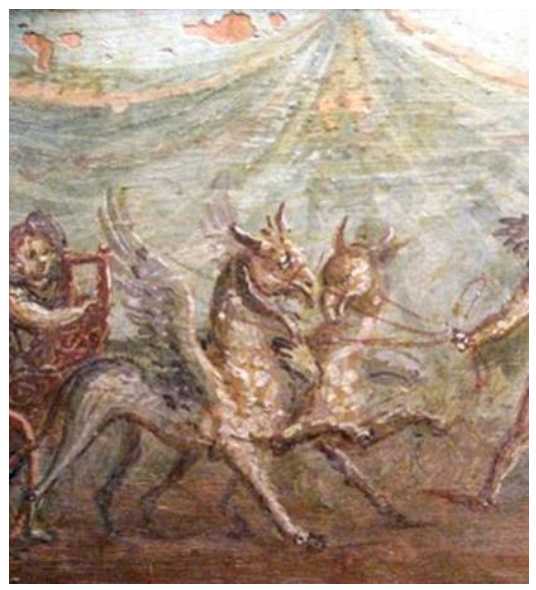

Figure 5.2: Detail of Griffons, Painting from Pompeii, National Archaeological Museum, Naples

\section{Conclusion}

The stone pillar at the Northern Vahalkada/frontispiece of Abhayagiriya Stupa, Anuradhapura has been recorded in history by several archaeologists and art historians. But its inspirations of ancient Roman artistic traditions have never been discussed. This paper discussed three artistic motifs present in the said stone pillar analyzing, giving examples from Roman Artistic traditions. The description would provide the readers with a preliminary reading of the presence of foreign artistic traditions with special reference to Roman artistic influences. It shows how the artist has usurped the foreign elements in beautifying the local art by retaining the traditions associated. Such is visible in identifying the use of the motif of griffins on the column 
at the frontispiece of Abhayagiriya, under discussion. Though the element is clearly of foreign origin, it has been used to denote the same idea that of guardianship of wealth as done with the more oriental motifs of Nagarajas, Kubera, Sankhanidi and Padmanidhi.

\section{Recommendations And Acknowledgments}

The author extends sincere gratitude to Professor Bopearachchi for providing necessary details, pictures for the study and guidance throughout the research.

\section{References}

Biyanwila, A. (2019). Art of A Heritage: An analysis of the ornamentation and the foreign artistic influences on the coffee planters' fountain in Kandy, [Manuscript submitted for publication]

Bopearachchi, Osmund (2020). Roots of Sri Lankan Art. Department of Archaeology, Colombo.

De Vann, Michiel (2008). Etymological Dictionary of Latin and the other Italic Languages, Leiden.

Dio Cassius, (1917). Roman History, of the Loeb Classical Library edition, Vol. V

Encylopedia Britannica (2011). Candelabrum. In Britannica.com. Retrieved January 5, 2021, from https://www.britannica.com/technology/candelabrum

Friar, Stephen (1987). A Dictionary of Heraldry, Crown Publishers, New York

Mahawamsa, (Geiger, Wilhelm Trans.) (1856-1943). Pali Text Society, London

Kulatunga, T.G. (2014). Purana Abhyagiri Vihāraya (in Sinhala), Central Cultural Fund, Colombo.

Paranavitana, Senarath (1959). Chapter IX. Civilization of the early period: religion and art. In H.C. Ray (Ed.), History of Ceylon. (Vol. I) Ceylon University Press, Colombo. 
Rose, Charles Brian (2005). The Parthians in Augustan Rome, American Journal of Archaeology, (Vol.109).

Seneviratna, Anuradha (1994). Ancient Anuradhapura, Archaeological Survey Department, Colombo.

Smither, G. James (1993). Architectural Remains, Anuradhapura, Sri Lanka, revised and edited Culture, Colombo.

von Shroeder, Ulrich (1990). Buddhist Sculptures of Sri Lanka, Visual Dharma Publications Ltd., Hong Kong.

Wickremasinghe, Don Marno De Silva (1912). Epigraphia Zeylanica, (Vol. I). London. 